\title{
Sexting, Cyber-violence and Sexually Risk Behaviour Among College Students
}

\author{
Dea Kričkić \\ Elementary School "Ivan Meštrović" Drenovci and Elementary School "Davorin \\ Trstenjak" Posavski Podgajci, Croatia
}

Daniela Šincek

Josip Juraj Strossmayer University of Osijek, Faculty of Humanities and Social

Sciences, Croatia

Ana Babić Čike

Josip Juraj Strossmayer University of Osijek, Faculty of Humanities and Social

Sciences, Croatia

Abstract

This research explores the relationship between sexting, committing and experiencing cyber-violence, and risk sexually behaviour among college students. A total of 202 college students filled out an adjusted version of the Sex and Tech Survey Questionnaire (STSQ), the Committing and Experiencing Cyber Violence Scale (CECVS) and the subscale on sexually risk behaviour from the Youth Self-reported Delinquency and Risk Behaviours Questionnaire (SRDP-2007). It has been found that a total of $60.89 \%$ of the participants have sent a sexually explicit text message and/or video content at least once, $60.33 \%$ have received such content, and $13.12 \%$ have forwarded or shown the received content to other people. Furthermore, 3.5\% of the participants have experienced, and 2.01\% have committed, cyber-violence. The majority of the participants have sent explicit content to their boyfriends/girlfriends. Most of the participants perceived sexting as a kind of joke, as a gift to their partner or as an answer to receiving sexually explicit content, while a minority of the participants mentioned negative motives for practicing sexting, such as peer or partner pressure. Almost all of the participants were aware of the danger sexting bore, but most of them still indulged in sexting, noting its positive outcomes, such as the excitement that followed it. Both committing/experiencing cyber-violence and sexually risk behaviour correlate positively and moderately with sexting. Positive and moderate correlations were found between committing and experiencing cyber-violence. Also, positive but weak correlations were found between practicing/experiencing cyber-violence and sexually risk behaviour in real life. Predicting sexting by experiencing and committing cyber violence and sexually risk behaviour has shown that only sexually risk behaviour is significant predictor. Such behaviour likely serves as a mediator for the relationship between committing cyber-violence and sexting, yet it explains only $8.2 \%$ of sexting variance, while the model as a whole explains almost $20 \%$. The results indicate that different forms of risk behaviour are correlated, and that sexting is perceived not only as a risk behaviour, but as a behaviour that can be used to facilitate committed relationships in young adulthood.

Keywords: cyber-violence, sexting, sexually risk behaviour

\section{Introduction}

Sexuality and the behaviour connected to it bear many risks, but also many gains. The nature of human sexuality is especially seductive; scholars have linked this to our hormones (e.g., Christiansen, 2001) and, in an evolutionary perspective, to our genes' survival (e.g., Hiller, 2004). In 
an era that brought humans into a new relationship with privacy and exposure, sexting emerged. For the generation's "digital natives", information and communication technology (ICT) interferes with their sexuality in various ways, bringing an additional developmental task to our youth: to learn how to regulate their sexual behaviour in an ICT environment (Davidson, 2015). Sexting, sexually risk behaviour and cyber - violence are behaviours that include some risks, mainly in enduring possible negative outcomes in mental health. Sexting can start as something funny, but can end in feeling of betrayal and in shaming. Sexually risk behaviour can jeopardize both physical, and mental health (unwanted pregnancies or STDs, for instance). Cyber-bullying victims have reported increased levels of sorrow, even depression and suicide attempts in some cases, while the perpetrators show lack of empathy and learn that violence is profitable.

Sexting is defined as "interpersonal exchange of self-produced sexualized texts and above all images (photos, videos) via cell phone or the internet" (Döring, 2014, p. 1). Hudson (2011) defined sexting as a type of sexual communication that can be categorized into consensual sexting (marked by mutual respect, consent and absence of pressure, without harmful intentions, but can cause harm in cases of accidental sharing), sext-bullying (sharing private explicit material without permission with harmful intentions), illegal sexting (child pornography acquired through criminal adult-child communication), and at-risk sexting (results in various negative consequences, like job loss or divorce, but cannot be classified as sext-bullying or illegal sexting). Sexting prevalence among adolescents' ranges from $4 \%$ to 39\% for sending (Lenhart, 2009; National Campaign to Prevent Teen and Unplanned Pregnancy (NCPTUP), 2008; Strassberg, McKinnon, Sustaita \& Rullo, 2013, Van Ouytsel, Van Gool, Ponner \& Walrave, 2014; Ybarra \& Mitchell, 2014), and from 7\% to 48\% for receiving explicit material (Lenhart, 2008; Mitchell, Finkelhor, Jones \& Wolak, 2012; NCPTUP, 2008; Strassberg, McKinnon, Sustaita \& Rullo, 2013). Klettke, Hallford and Mellor (2014) reported on meta-analytical data on sexting prevalence among young adults, indicating that the estimated mean prevalence for receiving was $53.31 \%$, while the estimated mean prevalence for sending was $48.56 \%$ (with the exception of one study done on a representative sample that reported lower sending prevalence $-33 \%$ of participants).

Some types of sexting overlap with cyber-bullying and cyber-violence. Cyber-violence is violence, especially among children, via the Internet and ICT (Sincek, 2014). It includes cyber-bullying, which is aggressive, intentional and carried out by individuals or groups; victims of cyber-bullying usually cannot defend themselves (Smith, Mahdavi, Carvalho, Fisher, Russell \& Tippett, 2008). Differentia specifica among cyber - violence and cyber-bullying is that cyber-violence is a broader term and does not require explicit intention and specific frequency of repetition which is characteristic for cyber-bullying. Cyber-violence and cyber-bullying are characterized by a threat that is present 24/7 due to high levels of Internet availability through smart phones and other devices. The experience of these phenomena is best described as "carrying your enemy in your own pocket". The prevalence of cyber-violence and cyber-bullying ranges between $20 \%$ and $40 \%$ among children (Tokunaga, 2010), and between $8.6 \%$ and $38.7 \%$ in university student populations (Gahagan, Vaterlaus \& Frost, 2016; Kraft \& Wang, 2010; Kopecký, 2014; MacDonald \& Roberts-Pittman, 2010).

The most prevalent motives for sexting differ from study to study. Henderson (2011) found that most participants chose "to be sexy or initiate sexual activity" as their motive for sexting, Englander (2012) and NCPTUP (2008) found pressure as the main motive underlying sexting, while 
Kopecký (2011) reported that the most salient motive was to reduce boredom. In contrast, in NCPTUP (2008), more than $60 \%$ of teens claimed to use sexting to be "fun and flirtatious", more than half of teen girls sent explicit material as a "sexy gift", and more than $40 \%$ of the participants' motives for sexting was "as a joke" or to respond to having received similar material. Among the young adults who also participated in NCPTUP (2008), the main motive was to be "fun and flirtatious" (72\% of young women and $70 \%$ of young men); $59 \%$ sent explicit material as a "sexy present", and more than $40 \%$ sent it in response to having received similar material. The same research found that more than $70 \%$ of adolescents and young adults thought that sexting had serious negative consequences.

Risk sexual behaviour is defined as any behaviour that enhances the probability of negative outcomes, including pregnancy and STDs (Cooper, 2002). Klettke, Hallford and Mellor (2014) reported that three studies found that sexting was positively correlated with unprotected sex, and two studies found a connection between sexting and having sex after alcohol consumption. They also reported on studies that linked sexting with other types of risk behaviours (e.g., higher drug and alcohol use among "sexters"). Klettke, Hallford and Mellor (2014) reported that some studies had found a connection between sexting and sexually risk behaviour. However, although there is overlap between some forms of cyber-violence and some forms of sexting, there are also studies that have found no connection (two out of five studies in Klettke et al.'s paper on sexting and sexually risk behaviour). The prevalence of these behaviours depends strongly upon the sample and method. In this light, we decided to explore: (1) the prevalence of sexting and experiencing and committing cyber-violence among university students; (2) motives for and consequences of sending explicit material; and (3) the contribution of cyber-violence and sexually risk behaviour to explaining variance in sexting. Based on the data from previous studies, we expected that the prevalence of sexting would range from $4 \%$ to $50 \%$, while $8 \%$ to $35 \%$ of young adults were expected to be involved in cyber-violence. We also expected that the most salient motives would be to be "fun and flirtatious" and to give a "sexy gift". Moreover, sexually risk behaviour and both types of cyber-violence were expected to be significant predictors of sexting.

\section{Subjects and Methods}

\section{Procedure}

The ethics committee of the Department of Psychology, Faculty of Humanities and Social Sciences J. J. Strossmayer University of Osijek, approved this research as part of the graduate thesis of first author and under supervision of second author. Informed consent was obtained from the participants. The data were collected during the spring semester of the 2015-2016 academic year at the Faculty of Agriculture in Osijek. The researcher distributed the surveys (which were in paper-and-pencil format), and students completed them independently and anonymously during regular classes.

\section{Participants}

Undergraduate and graduate students of the Faculty of Agriculture in Osijek participated in this research $(N=202)$. They were chosen as a group that can be assumed not to differ significantly 
from students' population on phenomena relevant for this research. In terms of gender, 88 participants were male (43.6\%). Their ages ranged from 18 to $27(M=20.96, S D=1.572)$. More than half of the participants stated that they were in a serious relationship ( $N=107$, or $53 \%), 15$ participants (7.4\%) said that their relationship was a non-committed relationship, 22 (10.89\%) stated that they were single, but occasionally had intercourse with temporary partners, while 7 (3.5\%) participants had a sexual, non-romantic relationship. Two participants were married, one was engaged, and one was in an open relationship.

On average, participants owned four devices with Internet access $(M=3.96, S D=2.104)$, and $77.2 \%(N=156)$ had non-stop Internet access, meaning that they were continually logged on to different social media accounts, e-mail addresses and instant messaging apps, so they received all their messages in real time. On workdays, they would spend almost five hours a day $(M=4.74$, $S D=5.629)$ on the Internet, and even longer on weekends $(M=5.63, S D=3.466)$.

\section{Measures}

Major sociodemographic information (age, gender) and information regarding Internet use and relationship status was collected.

The Committing and Experiencing Cyber Violence Scale (CECVS) (Šincek, Tomašić Humer, Duvnjak \& Milić, 2015) used here was an adaptation of scale developed by Cetin, Yaman \& Peker (2011). General statements from the original scale were concretised (e.g., the item "gossip on the Internet" was replaced by, "I gossip about others on the Internet"). Some behaviours more relevant to children and adolescents, such as "They wanted me off or I was excluded from a group on the Internet", were added to the scale. The committing violence subscale included 21 questions, and the experiencing violence subscale consisted of 22 items. Participants were asked to rate the frequency of their experiencing/committing violence on a five-point Likert-type scale ( $1=$ never, 5 =always). Higher scores indicated that the participant experienced/committed a particular behaviour more frequently. The calculated internal consistency coefficients were $\alpha=0.88$ and $\alpha=0.89$, respectively, for experiencing and committing violence.

The Sex and Tech Survey Questionnaire (STSQ) (NCPTUP, 2008) was adjusted for this study due to changes in ICT use (e.g., text messages are used less often due to an increase in the popularity of messengers). The questionnaire aims to explore sexting during the last year, and consists of three parts: personal experience with sexting, attitudes toward sexting and perceptions of others' sexting experience. For the purposes of the current study, data about personal experiences were used. Participants were asked to rate the frequency with which they had sent/received explicit material in the previous year on a five-point Likert-type scale ( $1=$ never, $5=$ on daily basis). They could choose among the listed senders/targets of explicit material, motives for sending and feelings aroused by received sexts - it was possible to choose more than one option. The calculated internal consistency coefficient was $\alpha=0.91$.

Sexually risk behaviour. The subscale of sexually risk behaviour from the Youth Self-Reported Delinquency and Risk Behaviours Questionnaire (SRDP-2007) (Ručević, Ajduković \& Šincek, 2009) consists of four items that explore involvement in risk sexual behaviours during the past year. The participants were asked to rate the frequency with which they had engaged in these behaviours on 
Dea Kričkić, Daniela Šincek, Ana Babić Čike: Sexting, Cyber-violence and Sexually Risk Behaviour Among...

a four-point scale (possible answers: $0 ; 1-2 x ; 3-4 x ; 5 x$ or more). The internal consistency coefficient was $\alpha=0.80$ in previous research, but in this research, it was markedly lower $(\alpha=0.64)$.

\section{Statistical Analyses}

The data were analysed using the statistical package SPSS version 20.0 (SPSS Inc., Chicago, IL). The collected data are shown with descriptive statistical parameters. The research questions are answered using frequencies, percentages, Pearson's correlation and hierarchical regression analyses.

\section{Results}

In Table 1, the descriptive statistics for the main variables in this research are shown. These results suggest that the distributions are positively asymmetric.

Table 1 Descriptive Statistics of the Main Variables

\begin{tabular}{|c|c|c|c|c|}
\cline { 2 - 5 } \multicolumn{1}{c|}{} & Sexting & Experiencing Cyber-violence & Committing Cyber-violence & Sexually Risk Behaviour \\
\hline M & 11.17 & 29.17 & 27.00 & 3.61 \\
\hline SD & 4.423 & 7.921 & 6.704 & 2.581 \\
\hline Min. & $8(\min .8)$ & $22(\min .22)$ & $21(\min .21)$ & 0 (min. 0) \\
\hline Max. & $26(\max .40)$ & $76(\max .110)$ & $72(\max .110)$ & 11 (max. 16) \\
\hline
\end{tabular}

Legend: $M$ - mean; $S D$ - standard deviation, Min. - minimum, Max. - maximum

Regarding experiencing cyber-violence, 23 participants (11.73\%) reported that they had not experienced any kind of cyber-violence in the previous year, and for committing cyber-violence, 19 participants (9.55\%) stated the same. To determine the percentage of participants involved in cyber-violence, cut-off point results were used -42 for committing and 44 for experiencing cyber-violence - based on the logic described in Đuraković, Šincek and Tomašić Humer (2014). These results indicate that the participants, on average, gave an answer of 2 or higher (meaning that they were, at least $2=$ rarely involved in cyber-violence). Based on these criteria, seven participants (3.57\%) had experienced cyber-violence, and four (2.01\%) had committed cyber-violence. In some of our previous research (e.g., Šincek, Tomašić Humer \& Duvnjak, 2015), we used different criteria: all participants who gave an answer of 4 (often) or 5 (always) on at least one item were categorized as involved in cyber-violence. Based on these criteria, our participants could be divided into four groups: 8 (3.96\%) were categorized as victims, 24 (11.88\%) as bullies, $10(4.95 \%)$ as victims/ bullies, and $160(79.21 \%)$ as uninvolved, meaning that $20.79 \%$ of the participants were involved in cyber-violence.

Almost 26\% ( $N=52)$ of participants denied having engaged in any sexting activities in the previous year, and 20 participants (10.31\%) said that they had not committed any of the four risk sexual behaviours in the previous year.

In Table 2, the frequency with which participants were involved in different types of sexting are presented. More than half of participants had sent a sexy message in the past year, and a quarter had sent a sexy photo/video at least once in the past year $(60.89 \%$ sent either a message or a photo/video), but only $1 \%$ of participants had posted their explicit photo/video publicly. The 
data in Table 2 suggest that more participants had received explicit messages (64.36\%) or photos/ videos (49.01\%); in total, $67.33 \%$ had received either a sexy message or a photo/video. Almost one-fifth of participants who had received an explicit message or photo/video had shared it or shown it to other people.

Table 2 Participants' Involvement in Different Types of Sexting

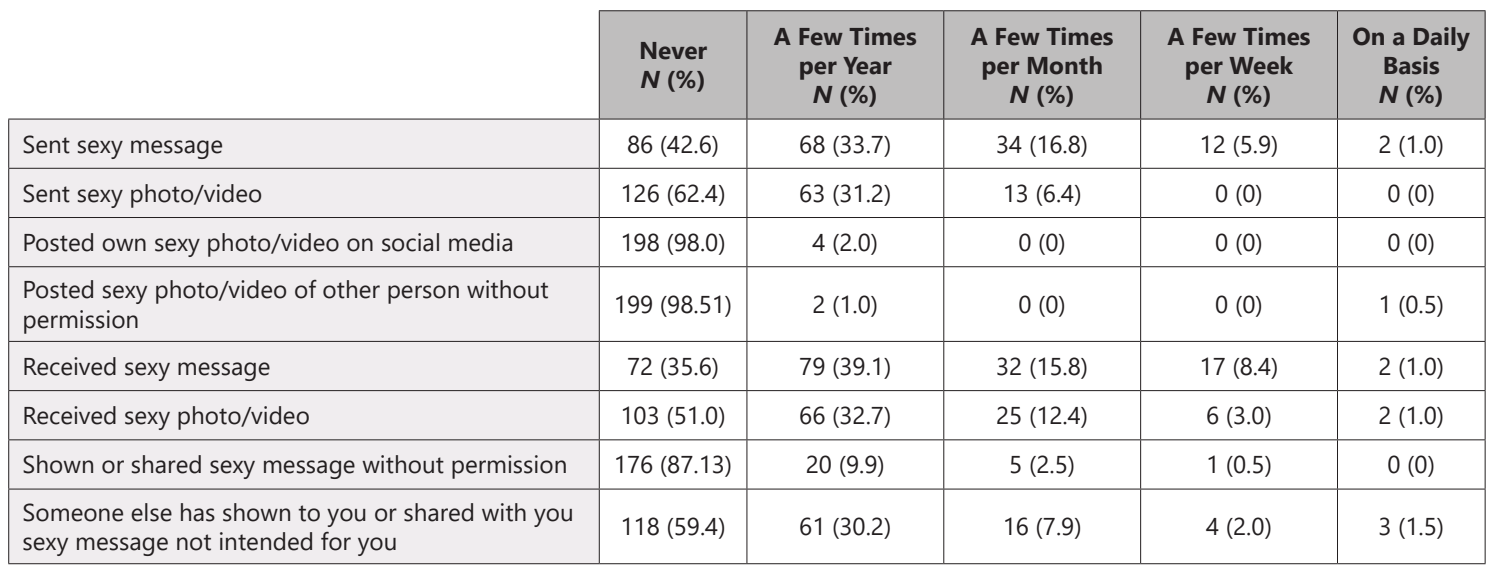

In Table 3, data regarding the sources and targets of explicit materials are presented. Current boyfriend/girlfriend is both a main source and a main target of explicit material, followed by an occasional partner and a good friend.

Table 3 Sources and Targets of Explicit Messages and Photos/videos

\begin{tabular}{|l|c|c|}
\hline Source/target & Received from (\%) & Sent to (\%) \\
\hline No one & 32.7 & 39.1 \\
\hline Boyfriend/girlfriend & 55.4 & 50.0 \\
\hline Someone I dated or "hooked up" with & 11.4 & 7.4 \\
\hline One or more good friends & 10.9 & 4.0 \\
\hline Someone I like, but am not in relationship with & 7.4 & 5.9 \\
\hline Someone I met via Internet & 3.0 & 4.0 \\
\hline Someone I would like to date or "hook up" with & 3.0 & 2.0 \\
\hline Ex-boyfriend/ex-girlfriend & 1.5 & 1.0 \\
\hline Unknown person & 0.5 & 0 \\
\hline
\end{tabular}

To explore motives for sexting, we asked our participants to choose what motivated them to sext. They could choose more than one motive. The most and least frequently chosen motives are shown in Table 4. The percentage of participants who did sext and who chose particular motives is shown in parentheses. Joking, reciprocity and "as a sexy gift" are the most frequently chosen motives, suggesting that it is seen more as a positive than a coerced behaviour. Still, $13 \%$ of these young adults did say that their motivation was pressure from their partner, and $5 \%$ did it under a friend's pressure. 
Dea Kričkić, Daniela Šincek, Ana Babić Čike: Sexting, Cyber-violence and Sexually Risk Behaviour Among...

Table 4 Particular Motives Chosen by Participants

\begin{tabular}{|l|l|c|}
\cline { 2 - 3 } \multicolumn{1}{c|}{} & Reason for sexting & $\boldsymbol{N}(\%)$ \\
\hline Motives most frequently chosen & As a sexy gift for girlfriend/boyfriend & $74(60.16)$ \\
\hline \multirow{2}{*}{ Motives least frequently chosen } & It was a joke & $55(44.72)$ \\
\cline { 2 - 3 } & I responded upon receipt & $51(41.46)$ \\
\hline & To be noticed & $18(14.3)$ \\
\hline & Girlfriend/boyfriend pressured me & $16(13.01)$ \\
\cline { 2 - 3 } & Friend pressured me & $6(4.88)$ \\
\cline { 2 - 3 } &
\end{tabular}

Table 5 shows that receiving an explicit message mostly elicited positive feelings, especially if the sender was the current partner. Excitement, happiness and feeling "horny" were the most salient feelings after receiving explicit material.

Table 5 Most Frequently Experienced Feelings After Receiving Explicit Material

\begin{tabular}{|c|c|c|c|c|c|}
\hline Feeling & $N$ & $\%$ & Sender & $N$ & $\%$ \\
\hline \multirow[t]{6}{*}{ Excited } & 70 & 51.47 & Girlfriend/boyfriend & 61 & 87.4 \\
\hline & & & Someone I like & 3 & 4.29 \\
\hline & & & Friend & 2 & 2.86 \\
\hline & & & Someone I dated or "hooked up" with & 2 & 2.86 \\
\hline & & & Someone I met via the Internet & 2 & 2.86 \\
\hline & & & Someone I would like to date or "hook up" with & 1 & 1.43 \\
\hline \multirow[t]{5}{*}{ Happy } & 57 & 41.91 & Girlfriend/boyfriend & 49 & 85.97 \\
\hline & & & Friend & 5 & 8.77 \\
\hline & & & Someone I dated or "hooked up" with & 1 & 1.75 \\
\hline & & & Someone I met via the Internet & 1 & 1.75 \\
\hline & & & Someone I would like to date or "hook up" with & 1 & 1.75 \\
\hline \multirow[t]{5}{*}{ "Horny" } & 53 & 38.97 & Girlfriend/boyfriend & 45 & 84.91 \\
\hline & & & Friend & 3 & 5.66 \\
\hline & & & Ex-boyfriend/ex-girlfriend & 2 & 3.77 \\
\hline & & & Someone I met via the Internet & 2 & 3.77 \\
\hline & & & Someone I would like to date or "hook up" with & 2 & 3.77 \\
\hline
\end{tabular}

We aimed to find an answer to the last research problem in this paper by exploring the (inter) correlations between sexually risk behaviour, and experiencing and committing cyber-violence, and the contribution of these in explaining the variance in sexting.

Intercorrelations between the predictors and their correlations with the criteria are shown in Table 6. All predictors correlate with sexting positively and moderately; the intercorrelation between committing and experiencing cyber-violence is also positive, but much larger. In contrast, cyber-violence correlates positively with offline sexually risk behaviour, but these correlations are small. 
Table 6 Intercorrelations Between Sexting, Experiencing and Committing Cyber-violence, and Sexually Risk Behaviour

\begin{tabular}{|c|c|c|c|c|}
\hline Variable & Sexting & $\begin{array}{c}\text { Experiencing } \\
\text { Cyber-violence }\end{array}$ & $\begin{array}{c}\text { Committing } \\
\text { Cyber-violence }\end{array}$ & $\begin{array}{c}\text { Sexually Risk } \\
\text { Behaviour }\end{array}$ \\
\hline Sexting & 1 & $.310^{\star *}$ & $.333^{\star *}$ & $.354^{* *}$ \\
\hline Experiencing cyber-violence & & 1 & $.657^{\star *}$ & $.168^{\star}$ \\
\hline Committing cyber-violence & & & 1 & $.186^{\star}$ \\
\hline Sexually risk behaviour & & & & 1 \\
\hline
\end{tabular}
${ }^{*} p<.05,{ }^{* *} p<.01$

The results of the hierarchical multiple regression analysis are shown in Table 7. Experiencing cyber-violence was entered in the first step, committing cyber-violence was added in the second step, and sexually risk behaviour in the third step. Experiencing cyber-violence was significant in the first step and explained $9 \%$ of sexting variance, but became non-significant after the addition of committing cyber-violence. Adding committing cyber-violence, which was a significant predictor of sexting in the second step, explained an additional $2.5 \%$ of the variance of criteria. Finally, sexually risk behaviour was added in the third step, and this was the only significant predictor in that step, explaining an additional $8.2 \%$ of sexting variance, suggesting that it probably serves as a mediator of the relationship between cyber-violence and sexting.

\section{Table 7 Results of HRA with Sexting as Criterion}

\begin{tabular}{|c|c|c|c|c|c|c|c|}
\hline Model & Predictor & $\boldsymbol{R}$ & $R^{2}$ & $\Delta R^{2}$ & $\boldsymbol{F}$ & $\beta$ & Partial $r$ \\
\hline 1st step & Experiencing cyber-violence & .299 & .90 & & $16.437^{\star \star}$ & $.299 *$ & \\
\hline \multirow[t]{3}{*}{ 2nd step } & & .340 & .115 & .025 & $10.825^{\star *}$ & & \\
\hline & Experiencing cyber-violence & & & & & .174 & .144 \\
\hline & Committing cyber-violence & & & & & $.204^{*}$ & .168 \\
\hline \multirow[t]{4}{*}{ 3rd step } & & .445 & .198 & .082 & $13.552^{* *}$ & & \\
\hline & Experiencing cyber-violence & & & & & .147 & .128 \\
\hline & Committing cyber-violence & & & & & .162 & .140 \\
\hline & Sexually risk behaviour & & & & & $.294^{\star *}$ & .305 \\
\hline
\end{tabular}

Legend: ${ }^{*} p<.05 ;{ }^{* *} p<.01 ; R$ - coefficient of multiple correlation; $R^{2}$ - coefficient of determination; $F$ - F-test; $\beta$-standardized coefficient

\section{Discussion}

The main aim of the paper was to explore the relationship between sexting, committing and experiencing cyber-violence, and risk sexually behaviour among college students. To achieve this aim we decided to explore: (1) the prevalence of sexting and experiencing and committing cyber-violence among university students; (2) motives for and consequences of sending explicit material; and (3) the contribution of cyber-violence and sexually risk behaviour to explaining variance in sexting.

All of our participants came from only one faculty (Faculty of Agriculture) since we did not find any particular reason to expect that these students differ from student's population in general in any of the relevant features (level of sexting, motives for sexting, cyber-violence and sexually risk behaviour). Slightly over quarter of the participants (26\%) claimed that they were not engaged in any kind of sexting activities in the previous year. The most frequent sexting activity is sending or receiving sexy message. More than half of participants had sent (57.4\%) or received (64.4\%) sexy 
message at least for a few times in the past year. Involvement rates here are higher than in Klettke, Hallford and Mellor's (2014) meta-analytical study (53.31\% for receiving and $48.56 \%$ for sending). Hudson, Fetro and Ogletree (2014) point out that higher ICT availability (particularly smart phones) makes sexting easier. Support for these claims can be found in more recent research done in the USA on comparable sample (Drouin, Coupe and Temple, in press) that reports similar prevalence as found in our research.

Although the participants were aware of the need to maintain their privacy and were reluctant to share their own explicit material publicly, $20 \%$ of young adults who had received explicit material did not respect the privacy of the sender and had shared it or shown it to others without the sender's permission. This clearly points to the importance of promoting respect of other people's privacy, even in young-adult settings. Not respecting others' privacy while sexting can easily transfer the perception of this behaviour from "fun and exciting" toward humiliating and degrading, possibly even bullying.

To determine cyber-violence prevalence, we used two different criteria. Based on the first criteria, seven participants (3.57\%) had experienced cyber-violence, and four (2.01\%) had committed cyber-violence which is lower than in previously conducted research on young adults (Gahagan, Vaterlaus \& Frost, 2016; Kraft \& Wang, 2010; Kopecký, 2014; MacDonald \& Roberts-Pittman, 2010). Based on the second criteria, 42 participants (20.79\%) were involved in cyber-violence (majority of them categorized as bullies or victim/bullies). This result is in accordance with the previously mentioned results regarding prevalence among young adults, but this also clearly shows how percentage of involvement depends on the definition and the method used. This is not only a methodological question; it also has relevance for treatment. In this research, most participants marked that they were gossiping via the internet (77.7), which could be seen as a benign activity; however, victims do mention gossiping as a source of their pain. On the other hand, adolescents in our preventive program "No to e-violence" (Babić Čikeš, Milić, Šincek and Tomašić Humer, 2016) did not see gossiping as important or harmful to others. They even expressed that those who felt victimized by some sorts of cyber-violence were "weak" and should toughen up emotionally, which clearly shows the importance of enhancing empathy in this type of treatment.

Motives for sexting and consequences of sexting were also examined. Half of the participant said that sexting occurred among them and their boyfriend/girlfriend. The percentage of explicit messages sent to boyfriend/girlfriend (55.4\%) found in this research is almost the same as percentage of sexting to committed partner (56\%) in Drouin, Coupe and Temple, (in press), although we used different measures. This is probably a result of the sample's characteristics (more than half of the participants in our sample were in a serious relationship), but it also points to an alternative approach to sexting. Most research refers to sexting as something risk, and omits to recognize that consensual sexting could heighten the quality of a romantic relationship. Support for alternative view on sexting can be found in the qualitative study done by Albury and Crawford (2012). They wrote about the sadness of a young man who found out that all the explicit videos with his soonto-be ex-girlfriend had been erased; he described those videos as funny, personal and intimate, and as something that helped maintain the relationship. Our participants report that they experienced mostly positive feelings after receiving an explicit message, especially if the sender was the current partner. Excitement, happiness and feeling "horny" were the most frequent emotional response 
on receiving explicit material. This was expected, as the data show that the romantic partner was the most frequent receiver and sender of sexts. Our participants did not report having received significant amounts of unwanted explicit material, and, as mentioned previously, the majority of them were involved in a serious relationship. Delevi and Weisskirch (2013) found that young adults were more prone to sext when in a serious relationship, and that female participants needed more commitment in a relationship in order to engage in sexting. Drouin, Coupe and Temple, (in press) found that relationship type was only significant predictor in several analysis showing that sexting in committed relationship was connected with more positive consequences, less negative consequences, and more sexting comfort. Motives for sexting chosen by our participants (joking, reciprocity and "as a sexy gift" are the most often) also indicate that sexting among young adults is more positive than a coerced behaviour. Contrary to that, some participant did say that they did sext under peers' or partners' pressure, which raises concern although this type of motivation is significantly less present than among adolescent girls in NCPTUP (2008) study. Compared to NCPTUP (2008) data on young adults, our data show similar percentages for sending explicit material as a sexy gift to a romantic partner or in response to received message. In our sample, promoting themselves as "fun and flirtatious" was not as highly represented, but sexting as a joke was very widespread.

The most relevant problem for the aim of this paper, specific contribution of cyber-violence and sexually risk behaviour in explaining of sexting was examined via HRA. Prior to that, correlations among predictors were analysed. It was found that committing and experiencing cyber-violence correlation is positive, and large which, at least to some degree can be attributed to similarity in measures. Both types of cyber-violence correlate positively with offline sexually risk behaviour, but these correlations are small.

Our model explained $19.8 \%$ of sexting variance in total. Previously entered predictors cease to be significant after entering predictor in second and in third step of HRA. Since there is significant correlation among predictors, and every predictor is significantly correlated with sexting, and these correlations became insignificant after entering predictor in next step, it indicates on probable mediation. Those involved in more cyber-violence were also more involved in sexting. Also, those exhibit more often sexually risk behaviour, sext more, and sexually risk behaviour serves as a mediator among cyber-violence and sexting. Given the current lack of findings regarding the relationship between cyber-violence and sexting, and given that some types of sexting can be categorized as sext-bullying, thereby linking sexting and cyber-violence, our data can be seen as a motivation for future research to help to clarify these relationships. Our results are in accordance with previous findings, which have indicated that sexting is positively correlated with sexually risk behaviour (Benotsch, Snipes, Martin \& Bull, 2013; Houck, Barker, Rizzo, Hancock, Norton \& Brown, 2014; Hudson, Fetro \& Ogletree, 2014; Rice et al., 2014). Possible role of sexually risk behaviour as a mediator of cyber-violence and sexting is an important finding suggesting, once again, that those youth that are at risk in one setting or behaviour, are more prone to risks in other areas, as suggested in Šincek, Tomašić Humer and Duvnjak (2017).

However, only one-fifth of sexting variance is explained, indicating that there are other possibly relevant predictors that link sexting to both negative elements (e.g., impulsivity) and positive ones (e.g., commitment, intimacy, trust). 
The limitations of the present study are primarily linked to the sample characteristics and the methodology used. Our sample is a convenience sample, and Klettke, Hallford and Mellor (2014) warned that prevalence is lower in studies using representative samples than in studies with convenience samples. The topic of this research is sensitive, and this could provoke more socially acceptable answers. As noted earlier, problems stemming from different definitions of terms, which lead to different criteria, are clearly shown in the case of measuring the incidence of cyber-violence.

Despite its limitations, this research offers insight into these risk behaviours. Future research should focus on the role of sexting not only as a risk behaviour, but also as a behaviour that can promote intimacy and improve the quality of romantic relationships. Insight into motives that incite risk behaviour and those that motivate consensual sexting could be very beneficial. Indeed, according to Cooper, Shapiro and Powers (1998), some motivations lead to risk behaviour, while others bring safe alternatives. Also, the relationship between sexting and attachment to the partner, as well as to personality variables, should be explored in future research. This will help in the treatment of this phenomenon, as well as in preventing the negative outcomes of sexting while promoting positive ones among young adults.

We believe that promoting care not only with one's own privacy, but even more so with the privacy of others, should be the focus of preventive activities; our participants did not share their own explicit material publicly, but $20 \%$ of those who received such material shared it without permission. One positive finding is that young adults, when compared to adolescents, are not as often motivated by pressure to sext. Nonetheless, even in this age group, 13\% sexted under pressure from a partner, and $5 \%$ under pressure from a friend's, suggesting that young adults could also profit from more encouragement to resist such pressure. Although the incidence of involvement in cyber-violence is lower than in comparable research, it is still $5.5 \%$ or $20 \%$ (depending on the criteria used). These young adults could benefit from selective prevention through psychoeducation about cyber-violence. Such programs should promote empathy, and even shame among those who are inclined to commit cyber-violence, while encouraging peaceful resistance and self-confidence among those who experience cyber-violence.

\section{Conclusion}

The present study has shown that sexting is performed by the majority of young adults, that they behave in this way mainly with their romantic partner (present, previous or "to be"), and, consequently, that their motivations for sexting can be seen as more positive (sexy gift, joke, reciprocity) than negative (feeling pressured). Although receiving explicit material makes them feel happy, excited or "horny", which are positive emotions, our data show that young adults do take risks. Cyber-violence and sharing received material is found in $20 \%$ of young adults. In the previous section, some ideas for preventive activities are given, based on our data. We have learned that sexting is related to cyber-violence and sexually risk behaviour, but these predictors explain only $20 \%$ of sexting variance, indicating that sexually risk behaviour serves as a mediator of cyber-violence. This also suggests that other important predictors, as mentioned in the previous section, should be included in future research. 


\section{References}

Albury, K., Crawford, K. (2012): Sexting, consent and young people's ethics: Beyond Megan's Story. Continuum. 26 (3). 463-473.

Babić Čikeš, A., Milić, M., Šincek, D., Tomašić Humer, J. (2016): Priručnik za prevenciju nasilja preko interneta. Filozofski fakultet. Osijek.

Benotsch, E.G., Snipes, D.J., Martin, A.M., Bull, S.S. (2013): Sexting, substance use and sexual risk behavior in young adults. Journal of adolescent health. 52. 307-313.

Cetin B., Yaman E., Peker A. (2011): Cyber victim and bullyng scale: A study of validity and reliability. Computers and Education. 57. 2261-2271.

Christiansen, K. (2001): Behavioural effects of androgen in men and women. Journal of Endocrinology. 170 (1). 39-48.

Cooper, M.L. (2002): Alcohol use and risk sexual behavior among college students and youth: evaluating the evidence. Journal of Studies on Alcohol, supplement. 14. 101-117.

Davidson, J. (2015): Sexting: Gender and teens. Springer.

Delevi, R., Weisskirch, R.S. (2013): Personality factors as predictors of sexting. Computers in Human Behavior. 29 (6). 2589-2594.

Döring, N. (2014): Consensual sexting among adolescents: Risk prevention through abstinence education or safer sexting? Cyberpsychology Journal of Psychosocial Research in cyberspace. 8 (1). article 1.

Drouin, M., Coupe, M., Temple, J. (in press): Is Sexting Good for Your Relationship? It Depends.... Computers in Human Behavior.

Englander, E. (2012): Low risk associated with most teenage sexting: A study of 617 18-year-olds. Retrieved 1 May, 2017 from http://webhost.bridgew.edu/marc/SEXTING\%20AND\%20 COERCION\%20report.pdf

Gahagan, K., Vatarlaus, J.M., Frost, L.R. (2016): College student cyberbullying on social networking sites: Conceptualization, prevalence, and perceived bystander responsibility. Computers in human behaviour. 55. 1097-1105.

Henderson, L. (2011): Sexting and sexual relationships among teens and young adults. McNair Scholars Research Journal. 7 (1). 31 - 39.

Hiller, J. (2004): Speculations on the links between feelings, emotions and sexual behaviour: are vasopressin and oxytocin involved? Sexual and Relationship Therapy. 19 (4). 393-412.

Houck, C.D., Barker, D., Rizzo, C., Hancock, E., Norton, A., Brown, L.K. (2014): Sexting and sexual behavior in at-risk adolescents. Pediatrics. 133 (2). 276-282.

Hudson, H.K. (2011): Factors affecting sexting behaviors among selected undergraduate students. Southern Illinois University at Carbondale.

Hudson, H.K., Fetro, J.V., Ogletree, R. (2014): Behavioral indicators and behaviors related to sexting among undergraduate students. American journal of health education. 45. 183-195.

Klettke, B., Hallford, D.J., Mellor, D.J. (2014): Sexting prevalence and correlates: A systematic literature review. Clinical psychology review. 34 (1). 44-53.

Kopecký, K. (2012): Sexting among Czech preadolescents and adolescents. The New Educational Review. 28 (2). 39-48. 
Dea Kričkić, Daniela Šincek, Ana Babić Čike: Sexting, Cyber-violence and Sexually Risk Behaviour Among...

Kopecký, K. (2014): Cyberbullying and other risks of internet communication focused on university students. Procedia-Social and Behavioral Sciences. 112. 260-269.

Kraft, E.M., Wang, J. (2010): An exploratory study of the cyberbullying and cyberstalking experiences and factors related to victimization of students at a public liberal arts college. International journal of technoethics. 1 (4). 74-91.

Lenhart, A. (2009): Teens and sexting: How and why minor teens are sending sexually suggestive nude or nearly nude images via text messaging. Pew Internet \& American life project. Retrieved 1 May, 2017 from http://www.pewinternet.org/2009/12/15/teens-and-sexting/

MacDonald, C.D., Roberts-Pittman, B. (2010): Cyberbullying among college students: Prevalence and demographic differences. Procedia-Social and Behavioral Sciences. 9. 2003-2009.

Mitchell, K.J., Finkelhor, D., Jones, L.M., Wolak, J. (2012): Prevalence and characteristics of youth sexting: a national study. Pediatrics. 129 (1). 1-8.

National Campaign to Prevent Teen and Unplanned Pregnancy \& CosmoGirl.com (2008): Sex and tech: Results from a survey of teens and young adults. Retrieved 26 February, 2009 from

Rice, E., Gibbs, J., Winetrobe, H., Rhoades, H., Plant, A., Montoya, J., Kordic, T. (2014): Sexting and sexual behavior among middle school students. Pediatrics. 134 (1). 21-28.

Ručević, S., Ajduković, M., Šincek, D. (2009): Razvoj upitnika samoiskaza rizičnog i delinkventnog ponašanja mladih (SRDP-2007). Kriminologija i socijalna integracija. 17 (1). 1-11.

Smith, P.K., Mahdavi, J., Carvalho, M., Fisher, S., Russell, S., Tippett, N. (2008): Cyberbullying: Its nature and impact in secondary school pupils. Journal of child psychology and psychiatry. 49 (4). 376-385.

Strassberg, D.S., McKinnon, R.K., Sustaita, M.A., Rullo, J. (2013): Sexting by highschool students: An exploratory and descriptive study. Archives of sexual behaviour. 42 (1). 15-21.

Šincek, D. (2014): Gender differences in cyber-bullying. In SGEM2014 Conference on Psychology and Psychiatry, Sociology and Healthcare, Education (Vol. 1, No. SGEM2014 Conference Proceedings, pp. 195-202). Stef 92 Technology.

Šincek, D., Tomašić Humer, J., Duvnjak, I. (2015): Navike korištenja interneta i njihova uloga u doživljavanju neugodnih iskustva na internetu. In: Orel, M., Jurjevčič, S. (Ed.), EDUvision 2015 »Modern Approaches to Teaching Coming Generation«, Ljubljana, 3rd \& 4th December 2015 - book of proceedings. EDUvision, Ljubljana. 143- 156.

Šincek, D., Tomašić Humer, J., Duvnjak, I. (2017): Correlates of problematic internet gaming - is there support for proneness to risk behaviour? Psychiatria Danubina. 29 (3). 302-312.

Šincek, D., Tomašić Humer, J., Duvnjak, I., Milić, M. (2015): Priroda korištenja informacijsko-komunikacijskih tehnologija (IKT) djece i mladeži u Republici Hrvatskoj - nacionalno istraživanje. Završna konferencija projekta "Safer Internet Centre Croatia: Making internet a good and safe place".

Tokunaga, R.S. (2010): Following you home from school: A critical review and synthesis of research on cyberbullying victimization. Computers in human behaviour. 26 (3). 277-287.

Van Ouytsel, J., Van Gool, E., Ponnet, K., Walrave, M. (2014): Brief report: The association between adolescents' characteristics and engagement in sexting. Journal of adolescence. 37. 1387-1391. 
Ybarra, M.L., Mitchell, K.J. (2004): Youth engaging in online harassment: Associations with caregiver-child relationships, Internet use and personal characteristics. Journal of adolescence. 27 (3). 319-336. 